
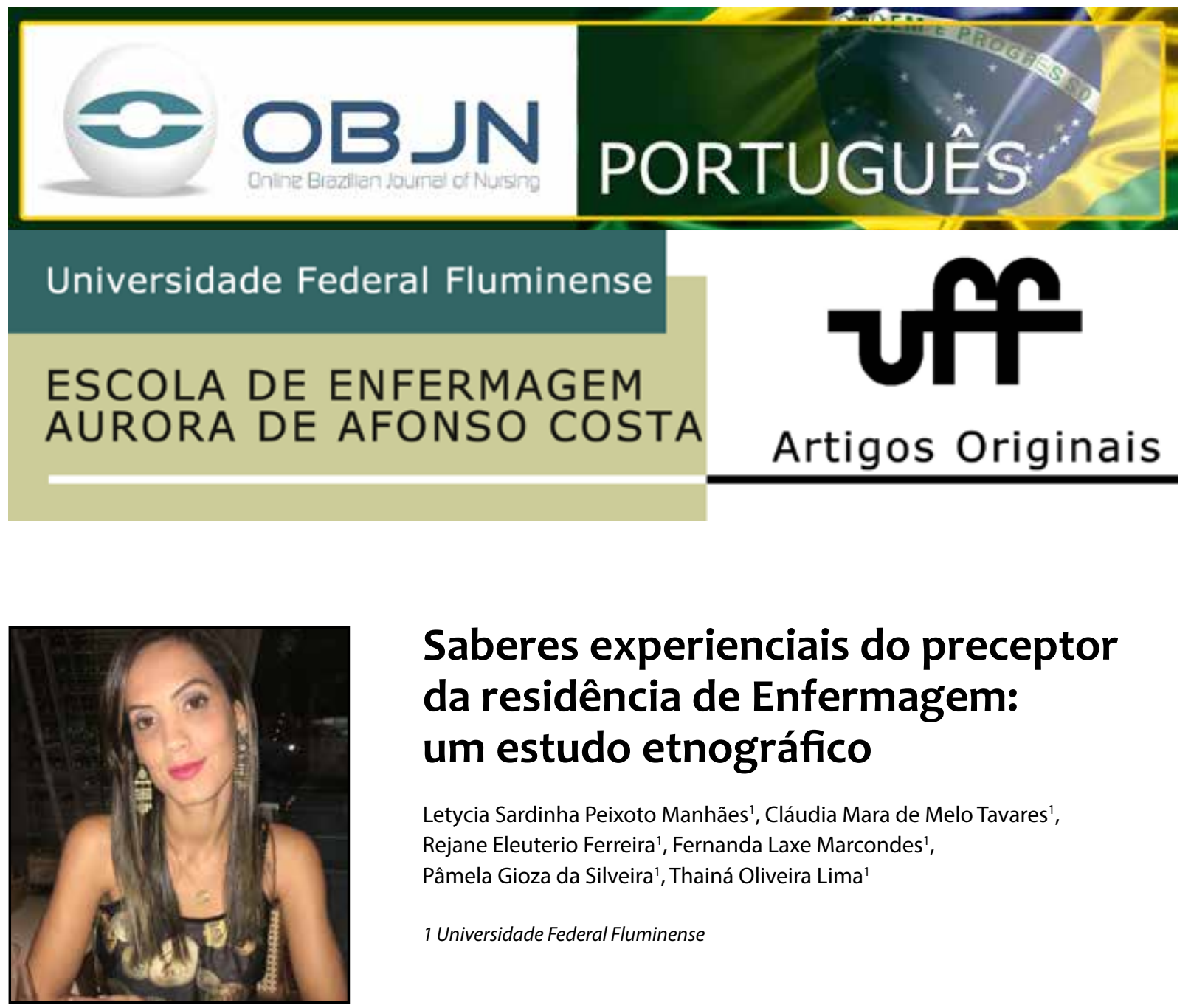

\title{
Saberes experienciais do preceptor da residência de Enfermagem: um estudo etnográfico
}

\author{
Letycia Sardinha Peixoto Manhães ${ }^{1}$, Cláudia Mara de Melo Tavares', \\ Rejane Eleuterio Ferreira', Fernanda Laxe Marcondes', \\ Pâmela Gioza da Silveira', Thainá Oliveira Lima' \\ 1 Universidade Federal Fluminense
}

\section{RESUMO}

Problema: o preceptor assume responsabilidades frente ao processo de ensinar. A orientação e o acompanhamento realizados com os residentes passam a ser um desafio para o próprio ambiente ao quais são expostos. Objetivos: identificar de que forma os saberes experienciais mobilizam saberes pedagógicos nos preceptores da residência em Enfermagem e discutir estratégias de capacitação para os preceptores. Método: pesquisa qualitativa e etnográfica. Realizaram-se seminário, observação participante e entrevista seguindo a Resolução 466/2012 do CNS, com parecer número 183.578. Resultado: os preceptores pontuaram fortemente a experiência como fundamento do saber como condição prévia para a ação educativa do preceptor. Discussão: a capacitação pedagógica do preceptor deve acontecer segundo demandas de aprendizado, de forma a norteá-los na construção de uma postura pedagogicamente ativa, possibilitando a ressignificação do trabalho e dos saberes. Conclusão: os saberes experienciais fornecem a integração com o contexto de trabalho; a própria experiência assegura a prática da profissão.

Descritores: Preceptoria; Educação em Enfermagem; Educação de Pós-Graduação; Hospitais de Ensino. 


\section{INTRODUÇÃO}

As instituições de ensino superior em Enfermagem têm o compromisso de formar profissionais capazes de exercer sua prática com cidadania em diferentes espaços coletivos, dispostos a compreender os desafios reais da sociedade e o seu papel enquanto dispositivos de mudança, articulando conhecimentos teóricos e práticos ${ }^{(1)}$.

Nessa construção de recursos humanos para área da saúde estão inseridos os preceptores de ensino da residência em Enfermagem, que são profissionais que acompanham, supervisionam e participam ativamente do processo educativo de formação de enfermeiros especializados nessa modalidade.

Para tanto, se faz necessário que esse preceptor detenha uma prática pedagógica capaz de suscitar nesses enfermeiros a ideação criativa, nova e sensível do saber, em que o aprender está relacionado ao descobrimento, à curiosidade, à compreensão, à construção e à reconstrução do conhecimento(2).

Os espaços de preceptoria podem ser oportunidades de encontros solidários com interação autêntica e viva para troca de experiências e vivências, que trazem à tona o papel da Enfermagem para o mundo real na saúde, onde o saber se faz por meio da aprendizagem significativa mediado pelos saberes experienciais construídos diariamente ${ }^{(3)}$.

Os saberes experienciais são destacados como o "carro-chefe" porque resultam da própria atividade docente, e são vivenciados por situações no espaço da escola e pelas relações estabelecidas tanto com os estudantes quanto com os colegas de profissão(4).

O preceptor deve ter conhecimento teórico, didático e político e a experiência dele é fundamental para unir e articular a graduação ao mercado de trabalho. Ele não exerce apenas um papel de formação de habilidades e técnicas específicas da profissão, mas também influencia na humanização, ética e na formação de opinião daqueles que o acompanham ${ }^{(5)}$.

$A$ residência é considerada uma modalidade de treinamento em serviço que permeia a aprendizagem pela prática cotidiana. Fundamenta-se em vivências com situações reais de trabalho, experiência em resolução de conflitos, relações interpessoais, habilidades específicas e aspectos éticos da profissão, de forma a oportunizar situações que o próprio processo de trabalho apresenta ${ }^{(6)}$.

Um estudo internacional enfatiza que a prática clínica possibilita o desenvolvimento de competências clínicas nos alunos. O preceptor se apresenta como facilitador para educação individualizada que favorece a articulação de conhecimento a habilidades práticas, colaborando com a aprendizagem reflexiva mediante a educação interdisciplinar ${ }^{(7)}$.

Sendo assim, os objetivos do estudo são identificar de que forma os saberes experienciais mobilizam saberes pedagógicos nos preceptores da residência em Enfermagem e discutir estratégias de capacitação pedagógica dos preceptores da residência na área.

\section{MÉTODO}

Pesquisa qualitativa de abordagem etnográfica, enfatizando que a etnografia trabalha no significado, na maneira própria que as pessoas veem não só a si mesmas como também suas experiências e o mundo que as cerca. Tem como princípio a relação prolongada no campo, a abertura ao conhecimento do senso comum a partir de uma visão de dentro e de perto que permite compreender a maneira de pensar e agir dos envolvidos no contexto da realidade pesquisada $^{(8)}$. O estudo foi realizado em dois hospitais 
de ensino (HE) vinculados a uma instituição de ensino superior no estado do Rio de Janeiro, que foram identificados como cenários $A$ e $B$. Os sujeitos do estudo foram enfermeiros que atuavam como preceptores e acompanhavam pós-graduandos de Enfermagem em modalidade residência, classificados como elegíveis conforme os critérios de inclusão: ser profissional de Enfermagem de nível superior (enfermeiro); estar em pleno exercício de suas funções; ser preceptor da residência de Enfermagem há no mínimo um ano. Os profissionais do serviço noturno foram excluídos, já que as atividades da residência não são desenvolvidas nesse turno.

Foram entrevistados 12 preceptores no total, sendo cinco no cenário $A$ e sete no cenário $\mathrm{B}$. Em ambos, o coordenador do setor e o enfermeiro da rotina foram entrevistados, e os demais contemplam o quadro de enfermeiros plantonistas do serviço diurno. Das 12 entrevistas realizadas, duas foram de elite, realizadas com os chefes dos setores e dez simplificadas, realizadas com os enfermeiros preceptores plantonistas e diaristas.

A construção de dados teve duração de quatro meses, a partir do primeiro trimestre de 2013, e somente iniciou a partir da aprovação dos comitês de ética CAAE de número 09475612.3.0000.5243, seguindo a Resolução 466/2012 do CNS com aprovação do parecer número 183.578. O primeiro mês foi destinado ao teste piloto, e três meses para coleta nos campos de pesquisa. Foram aproximadamente cinco semanas de duração para cada $\mathrm{HE}$, sendo a primeira reservada para a aproximação com o campo e com os sujeitos. As três semanas seguintes foram para observação-participante, que seguiu um roteiro específico, onde foram relacionados os objetivos da pesquisa e o referencial com as situações de trabalho do preceptor onde poderíamos encontrar dados. $\mathrm{Na}$ última semana foram realizadas as entrevistas individuais com perguntas fechadas e abertas, seguindo um roteiro preestabelecido, em espaço reservado, que permitiu ao participante responder de forma aberta e flexível. Elas foram gravadas e posteriormente transcritas com a ciência do participante.

Todos os sujeitos assinaram o Termo de Consentimento Livre e Esclarecido (TCLE) e foram identificados numericamente. Os dados foram analisados à luz do pensamento de Tardif e baseado nos pressupostos de uma pesquisa etnográfica.

\section{RESULTADOS}

O Quadro 1 representa o perfil profissional em relação a preceptoria dos sujeitos da pesquisa:

Quadro 1. Caracterização dos Sujeitos da pesquisa nos cenários A e B. Rio de Janeiro, 2013.

\begin{tabular}{|c|c|c|c|}
\hline VARIÁVEIS & $\begin{array}{l}\text { CARACTERI- } \\
\text { ZAÇÃO }\end{array}$ & \multicolumn{2}{|c|}{ SUJEITOS } \\
\hline \multirow{4}{*}{ SEXO } & \multirow{2}{*}{ FEMININO } & Cenário A & 04 \\
\hline & & Cenário B & 07 \\
\hline & \multirow{2}{*}{ MASCULINO } & Cenário $A$ & 01 \\
\hline & & Cenário B & 00 \\
\hline \multirow{6}{*}{ IDADE } & \multirow{2}{*}{ 30-40 ANOS } & Cenário A & 01 \\
\hline & & Cenário B & 01 \\
\hline & \multirow{2}{*}{ 41-50 ANOS } & Cenário A & 02 \\
\hline & & Cenário B & 03 \\
\hline & \multirow{2}{*}{ 51-60ANOS } & Cenário A & 02 \\
\hline & & Cenário B & 03 \\
\hline \multirow{10}{*}{$\begin{array}{l}\text { TEMPO DE } \\
\text { EXPERIÊN- } \\
\text { CIA PROFIS- } \\
\text { SIONAL }\end{array}$} & \multirow{2}{*}{$6-10$ anos } & Cenário A & 01 \\
\hline & & Cenário B & 01 \\
\hline & \multirow{2}{*}{$11-15$ anos } & Cenário A & 00 \\
\hline & & Cenário B & 02 \\
\hline & \multirow{2}{*}{$16-20$ anos } & Cenário A & 00 \\
\hline & & Cenário B & 02 \\
\hline & \multirow{2}{*}{$21-25$ anos } & Cenário A & 02 \\
\hline & & Cenário B & 01 \\
\hline & \multirow{2}{*}{$26-30$ anos } & Cenário $\mathrm{A}$ & 02 \\
\hline & & Cenário B & 01 \\
\hline
\end{tabular}




\begin{tabular}{|c|c|c|c|}
\hline \multirow{11}{*}{$\begin{array}{l}\text { TEMPO DE } \\
\text { EXPERIÊN- } \\
\text { CIA NA PRE- } \\
\text { CEPTORIA }\end{array}$} & ATÉ 02 anos & Cenário $B$ & 07 \\
\hline & \multirow{2}{*}{$6-10$ anos } & Cenário $\mathrm{A}$ & 01 \\
\hline & & Cenário B & 00 \\
\hline & \multirow{2}{*}{$11-15$ anos } & Cenário $\mathrm{A}$ & 00 \\
\hline & & Cenário B & 00 \\
\hline & \multirow{2}{*}{$16-20$ anos } & Cenário $\mathrm{A}$ & 01 \\
\hline & & Cenário B & 00 \\
\hline & \multirow{2}{*}{$21-25$ anos } & Cenário A & 02 \\
\hline & & Cenário B & 00 \\
\hline & \multirow{2}{*}{$26-30$ anos } & Cenário $\mathrm{A}$ & 01 \\
\hline & & Cenário B & 00 \\
\hline \multirow{4}{*}{$\begin{array}{l}\text { POSSUI } \\
\text { RESIDÊNCIA } \\
\text { EM ENFER- } \\
\text { MAGEM }\end{array}$} & \multirow{2}{*}{ SIM } & Cenário $\mathrm{A}$ & 03 \\
\hline & & Cenário B & 02 \\
\hline & \multirow{2}{*}{ NÃO } & Cenário $\mathrm{A}$ & 02 \\
\hline & & Cenário B & 05 \\
\hline
\end{tabular}

Fonte: autoria própria

Apenas um participante foi do sexo masculino, o que reafirma ainda a prevalência do sexo feminino na Enfermagem. Nenhum participante com menos de 30 anos que atendessem aos critérios de inclusão fora encontrado nos cenários.

Em relação à especialização, todos os preceptores de ambos os cenários possuem pelo menos uma pós-graduação lato sensu, e apenas um possui pós-graduação Stricto Sensu. No cenário $B$, todos os preceptores têm o mesmo tempo de experiência na preceptoria, pois o programa de residência incorporou esse setor como cenário de treinamento em serviço há pouco mais de dois anos.

A experiência profissional foi citada por períodos temporais e independentemente do ano de graduação de cada sujeito - alguns participantes, apesar de terem mais de 20 anos de graduados, só começaram a trabalhar anos mais tarde. Alguns ainda ficaram mais de 10 anos sem experiência profissional, e só a partir da aprovação em concurso público é que ingressaram na profissão.

Dos cinco entrevistados no cenário $A$, três sujeitos fizeram residência. Já no cenário $B$, dos sete entrevistados, apenas dois fizeram residência. Foi identificado nesses preceptores que já haviam feito residência um acompanhamento mais empático junto ao residente, o que demonstra que a própria experiência profissional, que se assemelha àquela que o residente está passando no momento, pode auxiliar o preceptor no desenvolvimento da prática pedagógica.

O próprio preceptor alega que ter como responsabilidade "obrigatória" a preceptoria dificulta que as ações sejam tão qualificadas, pois não se encontra em todos os enfermeiros do HE o perfil preceptor:

E acho que fica muito simples: "Ah! Ele é preceptor", mas qual é o perfil do preceptor? A gente não tem. Então, eu acho que isso são coisas que têm que ser construídas: qual é o perfil? O que ele precisa? Ele precisa ser só especialista? Ele precisa ter mestrado? Então, eu acho que são coisas a se pensar sim e precisa melhorar muito. (Preceptor 1)

Os preceptores tentaram descrever, durante as perguntas, que relação mantêm com a exterioridade dos seus saberes. Na opinião deles, uma boa formação se reflete num saber-fazer melhor, fundamentado numa prática orientada pelo mundo científico. Assim, a preceptoria permeia o mundo do saber-fazer e do saber-se; é pela experiência desses saberes que o conhecimento é construído, conforme o relato do $\operatorname{preceptor}^{(7):}$

Eu acho que influencia sim. Se você é um profissional recém-formado, você tem um olhar diferente de um profissional que já "tá" há dez anos na assistência. Então, até algumas coisas que eu sei que eu tenho que passar, foi por conta da experiência que eu tive anteriormente, até como residente não só como profissional agora da UTI neonatal. (Preceptor 7) 
Os preceptores pontuaram fortemente a experiência como fundamento do saber e condição prévia para a ação educativa do preceptor, de forma que o próprio trabalho acabe por fundamentar a prática preceptora - como se pode observar na fala abaixo:

Eu acho que isso é determinante porque uma pessoa - assim, a meu ver - que não tem experiência no que vai fazer, que não conhece o campo de atuação, não vai poder cobrar do residente ou de quem ele está supervisionando uma atuação direcionada. Se ele não conhece o assunto, ele não pode falar sobre isso. (Preceptor 3)

As complexas situações do trabalho de Enfermagem expõem esse residente à mobilização de diversos outros saberes. Ou seja, os saberes experienciais são precursores para convocar o próprio profissional ao desenvolvimento e ao uso dos outros saberes, por isso constituem, segundo o preceptor, o alicerce da prática:

Eu acho que a experiência faz toda a diferença. Eu condeno o aluno sair da graduação e acompanhar aluno. Se você não tem o tempo prático, vai faltar alguma coisa. Eu não posso dizer para ele como que eu atuo numa "parada" sem nunca ter atuado. Como é que eu vou ensinar? (Preceptor 6)

Tendo em vista essa necessidade de articulação da teoria com a prática e a responsabilidade da formação durante a residência, alguns preceptores acreditam que momentos de discussão das próprias situações clínicas também contribuiriam tanto com a formação do residente quanto na sua prática assistencial:
Eu acho que tinha que ter mais sessões clínicas, mais rounds de Enfermagem mesmo, momentos de discussão científica, apresentação de estudo de caso. É bem difícil, mas eu acho que tem que associar a prática profissional com a discussão clínica, com a prática científica: têm que andar juntos e sempre. (Preceptor 2)

A experiência não só de trabalho, mas da vivência que esse preceptor tem, que faz parte da sua história profissional e de vida, interfere na postura preceptora:

\begin{abstract}
A própria vivência da residência, da preceptoria, vai acrescentando experiência a essa atividade também. Quanto mais você exerce a atividade de preceptoria, mais isso vai acrescentando experiência. Porque a cada ano é um grupo novo, experiências novas, comportamentos novos. Então, durante os anos vai acrescentando também a experiência de como lidar com as situações e vai deixando você mais tranquila também para conduzir as situações. (Preceptor 1)
\end{abstract}

Enfatizaram a importância de se sentir"parte da instituição", e não marginalizados porque são preceptores e não docentes da universidade. Sentem a necessidade de estar mais engajados a cada grupo de residentes, para que todos criem uma relação desde o primeiro contato:

Eu acho que a gente precisa que o preceptor esteja engajado nos processos do hospital. Nós, os plantonistas, ficamos muito à margem do que acontece. O que a gente precisa discutir é uma maneira de como esse preceptor plantonista estar sempre acompanhando como aquele residente está evoluindo nos outros plantões, porque éo que acontece comigo. (Preceptor 3 ) 
É, na verdade, eu não fui preparada para ser preceptora. Eu fui preparada para ser enfermeira. Então, é a nossa prática jogada para eles, mas a gente não tem uma rotina, uma coisa assim com eles. (Preceptor 10)

Apontou-se a forma de abordagem em cada setor como um dos caminhos a ser traçado para a melhoria da preceptoria. Na mesma lógica de organização do programa, os profissionais entendem que deveriam se reunir, conversar, se encontrar para fazer o desenho de suas ações com os residentes do novo grupo, expor opiniões, acrescentar ideias com os outros colegas preceptores, acreditando ser uma questão pertinente aos responsáveis pela residência no serviço:

Eu acho que a gente poderia ter um momento, a cada período que vem um grupo novo, com todos os enfermeiros. Começar a fazer um roteiro do que a gente pode, a cada dia, ir orientando. Hoje em dia está muito solto; a gente teria que ter melhores condições de dar atenção. (Preceptor 9)

Alguns diálogos a seguir demonstram ideias, demandas e necessidades dos preceptores entrevistados em relação à capacitação profissional:

Eu acho que podiam ser feitos cursos ou encontros para preparar esse preceptor para saber realmente qual é o papel dele antes de os residentes chegarem. (Preceptor 7)

A distribuição de um roteiro, por exemplo, para o enfermeiro que está acompanhando o que aquele residente tem que alcançar no período de residência dele. (Preceptor 11)

Eu acho que a primeira coisa é treinar um grupo de preceptoria para que seja uma prática homogênea. Conscientizar a equipe do setor. Isso tudo eu acho que tem que ser feito um programa de educação continuada. (Preceptor 6)

Nesse sentido, alguns preceptores trazem reflexões sobre o que contemplaria uma capacitação estratégica para preceptoria:

O curso de preceptoria não tem que se deter na formação do conteúdo programático, e sim na maneira como ele tem que lidar com o residente. Interfacear esse saber com o ensinar. Porque nem sempre o preceptor tem esse bom senso. Porque há alguns dias da semana, algum momento do plantão, que o preceptor também está acometido por emoções, sejam pessoais, sejam profissionais. E se ele não tiver um entendimento do manejo desse relacionamento com o residente, ele acaba transferindo isso para o residente e o residente esmorece. Ele se afasta desse preceptor que pode ter muito domínio teórico, acadêmico e prático. (Preceptor 5)

A todo o momento, o preceptor expõe sua prática assistencial como centro dos seus saberes para lidar com a preceptoria. E assim, trazem uma reflexão de não fragmentação das áreas acadêmicas e assistenciais:

Eu acho que isso é uma coisa que a gente pode pensar em oferecer, capacitação para os nossos enfermeiros 
também. Isso também é um caminho, eu acho que a educação continuada tem que estar paralela a vários processos que são desenvolvidos na Enfermagem. Agora, o que eu vejo como impeditivo é a questão do servidor e do preceptor quererem isso, porque não deveria ser obrigatório deveria ser uma vontade. (Preceptor 1)

Para ampliar a discussão e refletir nos achados, baseado no pressuposto da etnografia que respeita o olhar sobre um fenômeno pela ótica do próprio sujeito que o vive, a discussão se dará em dois eixos temáticos que apontam para a experiência enquanto fundamento do saber e também como os preceptores poderiam ser capacitados.

\section{DISCUSSÃO}

A experiência de trabalho enquanto fundamento do saber: o alicerce da prática

Numa perspectiva tardifiana, se há um consenso de que os saberes não provêm de uma fonte única e que os preceptores tendem a operá-los de forma que os hierarquizem, onde os que são mais mobilizados no trabalho acabam por receber mais valor profissionalmente, os oriundos da experiência são o alicerce da prática e o da competência profissional, pois a experiência vai ser a condição para aquisição e produção dos seus próprios saberes.

Os saberes da experiência são definidos como um conjunto de saberes atualizados, adquiridos e exigidos na prática profissional. Eles defendem que os saberes da experiência não constituem um grupo de conhecimento, mas o próprio carro-chefe da competência profissional dos docentes ${ }^{(4)}$. São formados a partir de todos os outros e originados da prática e da vivência no contexto real e profissional.

Corroborando com essa ideia, a prática pedagógica não se resume a encontros teóricos - ela acontece na vivência do cotidiano, ou seja, pela experiência viva que essa prática se constitui como um evento social. Para que ela não se resuma a ações reprodutivistas, existem componentes essenciais - planejamento, avaliação, conteúdo, estratégias e recursos didáticos - permitindo que todos os envolvidos tenham sua participação assegurada e se consiga alcançar a transformação da realidade ${ }^{(1)}$.

Os preceptores tentaram descrever, durante as perguntas, que relação mantêm com a exterioridade dos seus saberes. Na opinião deles, uma boa formação se reflete num saber-fazer melhor e fundamentado, numa prática orientada pelo mundo científico, e uma prática fundamentada reflete numa preceptoria mais bem desenvolvida, o que tornou expressões como "Se você nunca fez, como vai ensinar a alguém?" frequentes durante as entrevistas.

A relação de exterioridade do preceptor com os saberes contribui para a valorização dos próprios saberes da experiência, pois é onde encontram meios de legitimar cada conhecimento, seja ele curricular, disciplinar ou de formação profissional. O próprio cotidiano faz com que o preceptor vivencie situações concretas que fazem necessária a mobilização da criação, da improvisação, da tomada de decisões, que permitem construir estratégias de sucesso para a ação pedagógica.

Os saberes experienciais são enraizados em um ensino que se desenvolve no contexto de diversas interações e representam os condicionantes para a atuação do professor ${ }^{(4)}$. O preceptor lida com esses condicionantes, que são relacionados às situações reais no trabalho, e trabalhar com eles acaba por ser formador. 
O saber é fruto de uma experiência intelectual e não de uma representação subjetiva. O saber-fazer apresenta a necessidade do domínio de ferramentas do trabalho, tem um cunho técnico e, se bem realizado, otimiza o tempo e produtividade no trabalho. Porém, é no saber-ser que os interesses pessoais vêm à tona. Inclui a personalidade, a curiosidade e a inovação, e é por essa perspectiva que o indivíduo se propõe ao novo, a enfrentar desafios e a aceitar mudanças ${ }^{(9)}$.

O preceptor, além de reafirmar o que Tardif fala sobre os saberes da experiência, cita um fator que também reitera os "fios condutores do saber". O preceptor que foi um residente de Enfermagem traz consigo uma sensibilidade à prática preceptora que contribui para compreender as demandas de aprendizado que o residente traz e se disponibiliza da melhor forma para ensiná-lo.

A aprendizagem ativa valoriza situações-problema que favoreçam o aprender a aprender, e a preceptoria pode propor reflexão sobre problemas cotidianos da profissão a fim de buscar o acontecido e propor a solução(6). As próprias situações de trabalho instigam o preceptor a buscar outras fontes de conhecimento para resolvê-las.

Os saberes experienciais fornecem a integração com o contexto de trabalho ao longo dos anos. Logo, um preceptor que está nessa prática há mais tempo tem uma "bagagem"melhor para o cargo, na medida em que a própria experiência assegura a prática da profissão e a própria experiência se transforma. O preceptor vai criando seus meios de ensinar, e pelos saberes experienciais também forma uma identidade, uma personalidade profissional.

\section{Como capacitar um preceptor}

Diante da problemática da pesquisa, um dos objetivos do estudo era traçar estratégias de capacitação para os preceptores, já que é notável a carência na formação para esse ofício. Tendo em vista que um estudo com uso da etnografia traz um fenômeno a partir da representação do próprio ser que o vivencia, a capacitação dos preceptores também precisaria partir da demanda do que eles acreditassem ser necessário e importante para sua qualificação.

Os preceptores, ao serem abordados para direcionar os autores sobre como qualificar um futuro profissional do cargo, responderam quase que instantaneamente as perguntas, como se tivessem já refletido sobre ou expressando um desejo de como eles gostariam de receber a capacitação para "lidar" (termo muito usado durante as entrevistas com os residentes).

É essencial que o preceptor tenha uma "disposição pedagógica" associada à sua prática com o residente de forma indissociável ao processo dialógico de ensino-aprendizagem, que se baseie na educação problematizadora e libertadora capaz de transpassar a mera transmissão de conteúdos e possibilitar caminhos de superação das dificuldades cotidianas e construção de soluções inovadoras ${ }^{(10)}$. Há de se pensar na perspectiva da educação como prática de liberdade para capacitar um preceptor, pois levando em consideração seres dialógicos e uma educação libertadora para o residente de Enfermagem, é preciso o profissional nos mesmos moldes, para que compreenda o que é, então, essa educação como prática de liberdade, o que é o "ser no mundo", como ser dialógico e como pronunciar sua realidade de forma autêntica, reflexiva, criativa e curiosa.

Acredita-se que os preceptores demandem uma organização e sistematização de suas ações em consonância com a instituição e o programa de residência, onde eles, de fato, possam se sentir parte do processo de formação de especialistas por meio da sua preceptoria. Os profissionais demonstram uma necessidade 
em se reconhecer como preceptores devido à recíproca da própria instituição. Nesse caso, um ponto para pensar sobre a capacitação seria a qualificação que pode ser feita com os preceptores e a não precarização de suas ações diárias e preceptoras.

A organização celular do trabalho docente não é apenas um dispositivo espacial, mas também temporal e social, visto que ela rege o tempo de trabalho e as formas de colaboração no seio da coletividade de trabalho dos estabelecimentos $^{(11)}$. A colaboração dos diversos atores, incluindo institucionais, para capacitação dos preceptores também se faz necessária.

Mais de um preceptor apresenta como estratégia de capacitação o planejamento de ações realizadas por eles mesmos, mediante um espaço coletivo de ideias que serão compartilhadas e desenvolvidas. Isso reafirma a ideia de que o saber também é social a partir do momento em que é compartilhado por um grupo de agentes que possuem uma formação em comum e que estão sujeitos aos mesmos condicionamentos e recursos, comparáveis por conta da estrutura coletiva em que se encontram ${ }^{(4)}$. Ou seja, são os próprios preceptores que podem de fato direcionar como exercerão a tarefa de maneira mais efetiva, qualificada, resolutiva para com a residência.

Os preceptores sentem a necessidade de planejamento nas suas ações. A falta de planejamento, segundo eles, expõe o trabalho à desqualificação, tendo em vista que não se programam para aquelas ações e não se preocupam em fazer diferente, pois não refletiram sobre os assuntos.

As necessidades do trabalho acabam por direcionar a preceptoria e contribuir para relações superficiais. Mas esse trabalho exige um investimento profundo, tanto do ponto de vista afetivo como cognitivo, nas relações humanas com os residentes.
Ainda na dificuldade de reconhecerem seu papel educativo, os preceptores assumem os residentes como uma "tarefa a mais", que os sobrecarrega e dificulta a própria assistência. Alguns não conseguem articular de uma maneira efetiva a prática assistencial às atividades preceptoras.

No decorrer da vida, o homem busca seu desenvolvimento pessoal e profissional, e assim ressalta-se que esses processos ocorrem tanto em situações de ensino formal quanto a partir de estudos independentes ou experiências vividas - especificamente na área da saúde, essa busca deve ser considerada ainda mais crítica ${ }^{(12)}$. Os autores pensam que muito além de oferecer cursos de capacitação, se encontra o desafio de qualificação da preceptoria. $O$ investimento nesse caso é institucional, setorial, pessoal e profissional, engloba vários fatores que incorporam o poder de decisão de cada ator envolvido para que, assim, realmente se pense em desenvolvimento profissional autêntico.

A preceptoria é voltada para o treinamento em serviço, assim como a especialização nos moldes de residência. A prática fundamentada é uma necessidade clara do dia a dia do preceptor e uma demanda que o residente traz consigo. Concomitante a isso, destaca-se que um bom programa de residência é essencial para o sucesso de enfermeiros que estão em transição na formação continuada. Para tanto, também se torna fundamental o investimento com foco no desenvolvimento de características e habilidades preceptoras ${ }^{(13)}$.

O ensino não pode ser descontextualizado da prática (ponto fundamental de discussão), pois o preceptor que abarca saberes disciplinares, curriculares, de formação profissional e principalmente da experiência acaba por se envolver no tecnicismo da profissão e também reconhece a importância do saber científico, mas sempre atrelado à prática. 
Os profissionais apontam a educação continuada também como uma forte estratégia de capacitação. Assim, reorienta-se esse conceito para o que é conhecido como educação permanente, que trabalha numa perspectiva coletiva, multiprofissional, e tem por objetivo a transformação de práticas, pois se fundamenta na resolução de problemas para fins de mudanças institucionais quando necessárias, favorecendo a apropriação ativa do saber científico e o fortalecimento de equipes $^{(14)}$.

Portanto, além de se pensar em estratégias que contemplem a política de educação permanente, é necessário pensar na identidade, na pessoa, na personalidade desse profissional a ser capacitado. O preceptor abarca saberes profissionais que vivificam sua prática e legitima sua vida profissional, trazendo consigo valores, crenças, cultura e ética, que merecem ser conhecidos e bem trabalhados.

É necessário pensar que o HE já é uma instituição formadora e constitui-se como a extensão da própria universidade, onde os enfermeiros que ingressaram nesse campo de trabalho já reconhecem o caráter educativo da instituição e não necessariamente podem se abster desse compromisso.

O preceptor deve conhecer e reconhecer primeiro seu papel educativo na residência de Enfermagem, para deixar um caminho à paixão por essa prática. O preceptor, mesmo diante de todas as dificuldades apresentadas, tem um papel importante e essencial na formação desses especialistas. É um profissional que merece investimento pela sua contribuição ao longo de toda residência - contribuição essa que envolve desgaste físico e emocional, disponibilidade, amor, conhecimento, fundamentação teórica e prática profissional. São muitos os saberes mobilizados por um preceptor num só dia de residência, imagine se levando em consideração seu papel ao longo dos dois anos do programa.

\section{CONCLUSÃO}

Os saberes da experiência brotam da própria experiência e por ela são validados. Ao mesmo tempo, se incorporam à construção individual e coletiva desses saberes a partir do cotidiano e da práxis, do saber-fazer e do saber-ser.

A questão do processo de trabalho sendo reflexo da forma como exercem a preceptoria faz pensar sobre os desafios que foram observados no complexo processo de trabalho da Enfermagem. A tentativa da realização desses papéis funde as responsabilidades do preceptor e do enfermeiro. Entretanto, a fusão de papéis, muitas vezes ainda não tão claros para o preceptor, pode fazer com que o investimento pessoal seja maior na assistência e a preceptoria fique à margem de suas ações. Porém, mesmo que a assistência se torne uma prioridade, as ações da preceptoria devem estar previstas no cotidiano do trabalho.

O preceptor sofre influência de fatores determinantes e condicionantes da sua prática educativa, tendo em vista os contextos institucional e setorial ao qual são submetidos, assim como valores e regras que interferem na relação dos saberes.

Os saberes experienciais fornecem a integração com o contexto de trabalho, e a própria experiência assegura a prática da profissão e se transforma. O preceptor vai criando seus meios de ensinar, e pelos saberes experienciais forma uma identidade profissional.

Compreende-se também que a capacitação pedagógica do preceptor deve acontecer segundo suas demandas de aprendizado, prevendo meios para norteá-lo na construção de uma postura pedagogicamente ativa nas ações preceptoras, possibilitando a ressignificação do trabalho e dos saberes.

Neste artigo não há a idealização de um preceptor, pois esse cargo tem caráter singu- 
larizado. A prática pedagógica torna-se subjetiva em alguns aspectos a partir das próprias experiências do preceptor. Assim, não existe um modelo, mas uma ética orientadora que vai direcionar o papel educativo dele.

No presente estudo destacaram-se como obstáculos epistemológicos o tempo de construção dos dados, o número de cenários abordados e de preceptores estudados, além do perfil de residência diferenciado em cada $\mathrm{HE}$. Entretanto, a pesquisa contribuiu para o início de uma compreensão do sujeito preceptor e de seus saberes mobilizados no esgotamento do cotidiano de trabalho da Enfermagem.

\section{REFERÊNCIAS}

1. Silva VC, Viana LO, dos Santos C2 mRGC. Social and pedagogical practice of the nurse-preceptor: a case study. Online braz j nurs [Internet]. 2014 March [Cited 2016 Jan 14]; 13 (1): 102-112. Available from: http://www.objnursing.uff.br/ index.php/nursing/article/view/4097. doi: http:// dx.doi.org/10.5935/1676-4285.20144097.

2. Silva OS, Dantas da Silva CMSLM, Figueiredo NMA. Images built on the graduation of the nurse from the tutorial scenario. JRFCO [Internet]. 2014 Jul [Cited 2016 Jan 14]; 6 (3): 1047-1057. Available from: http://www.seer.unirio.br/index. php/cuidadofundamental/article/view/3300>. doi:http://dx.doi.org/10.9789/2175-5361.2014. v6i3.1047-1057.

3. Dantas da Silva CMSLM, Silva OS. The production of meanings drawn by students in tutoring in undergraduate nursing. JRFCO [Internet]. 2014 Jan [ Cited 2016 Jan 14]; 6 (1): 168-182. Available from: http://www.seer.unirio.br/index. php/cuidadofundamental/article/view/2840>. doi:http://dx.doi.org/10.9789/2175-5361.2014. v6i1.168-182.

4. Tardif M. Saberes Docentes e Formação Profissional. 16. ed. Petrópolis: Vozes; 2014.

5. Rodrigues AMM, Freitas CHA, Guerreiro MGS, Jorge MSB. Preceptorship in the perspec- tive of comprehensive care: conversations with nurses. Rev. Gaúcha Enferm. [Internet]. 2014 June [cited 2016 Jan 14] ; 35 (2): 106112. Available from: http://www.scielo.br/ scielo.php?script=sci_arttext\&pid=S1983$-14472014000200106 \&$ Ing=en. http://dx.doi. org/10.1590/1983-1447.2014.02.43946.

6. Melo MC, Queluci GC, Gouvea MV. Problematizing the multidisciplinary residency in oncology: a practical teaching protocol from the perspective of nurse residents. Rev. esc. enferm. USP [Internet]. 2014 Aug [cited 2016 Jan 14]; 48( 4 ): 706-714. Available from: http://www.scielo. br/scielo.php?script=sci_arttext\&pid=S0080$-62342014000400706 \&$ Ing=en. http://dx.doi. org/10.1590/S0080-623420140000400019.

7. Carlson E. Precepting and symbolic interactionism -a theoretical look at preceptorship during clinical practice. J Adv Nurs; 69(2): 457-64, 2013 Feb. doi: 10.1111/j.1365-2648.2012.06047.x. Epub 2012 Jun 7.

8. Fava SMCL, Zago MMF, Nogueira MS, Dazio EMR. The experience of the illness and of the treatment for the person with systemic arterial hypertension: an ethnographic study. Rev. Latino-Am. Enfermagem [Internet]. 2013 Oct [cited 2016 Dec 21]; 21( 5): 1022-1029. Available from: http://www.scielo. $\mathrm{br} / \mathrm{scielo}$.php?script=sci_arttext\&pid=S0104$-11692013000501022 \&$ lng=en. http://dx.doi. org/10.1590/S0104-11692013000500003.

9. Tanabe LP, Kobayashi RM. Profile, competencies and digital fluency of nurses in the Professional Improvement Program. Rev. esc. enferm. USP [Internet]. 2013 Aug [cited 2016 Jan 14]; 47( 4 ): 943-949. Available from: http://www.scielo. br/scielo.php?script=sci_arttext\&pid=S0080$-62342013000400943 \&$ Ing=en. http://dx.doi. org/

10. $1590 /$ S0080-623420130000400024.10. Melo MC, Queluci GC, Gouvêa MV. Preceptoria de enfermagem na residência multiprofissional em oncologia: um estudo descritivo. Online braz j nurs [Internet]. 2014 December [Cited 2016 Dec 21]; 13 (4): 656-66. Available from: http://www. objnursing.uff.br/index.php/nursing/article/ view/4567. doi: http://dx.doi.org/10.5935/16764285.20144567.

11. Tardif M. O Trabalho Docente: Elementos para 
uma teoria da docência como profissão de interações humanas. 7. ed. Petrópolis: Vozes, 2012.

12. Bussotti EA, Leite MTM, Alves ACC, Cristensen K. Capacitação on-line para profissionais da saúde em três regiões do Brasil. Rev. Bras. Enferm. [Internet]. 2016 Oct [cited 2016 Dec 21]; 69 (5): 981-985. Available from: http://www.scielo. br/scielo.php?script=sci_arttext \&pid=S0034$-71672016000500981 \&$ Ing=en. http://dx.doi. org/10.1590/0034-7167.2016690506.

13. Shinners JS; Franqueiro T. Preceptor skills and characteristics: considerations for preceptor education. J Contin Educ Nurs; 46(5): 233-6, 2015 May. doi: 10.3928/00220124-20150420-04.

14. Peixoto LS, Gonçalves LC, Costa TD, Tavares, CMM, Cavalcanti ACD, Cortez EA. Educación permanente, continuada y de servicio: desvelando sus conceptos. Enferm. glob. [Internet]. 2013 Jul [Cited 2016 Jan 14]; 12 (29): 307-322. Available from: http://scielo.isciii. es/scielo.php?script=sci_arttext\&pid=S1695$-61412013000100017 \&$ lng $=$ es.
Todos os autores participaram das fases dessa publicação em uma ou mais etapas a seguir, de acordo com as recomendações do International Committe of Medical Journal Editors (ICMJE, 2013): (a) participação substancial na concepção ou confecção do manuscrito ou da coleta, análise ou interpretação dos dados; (b) elaboração do trabalho ou realização de revisão crítica do conteúdo intelectual; (c) aprovação da versão submetida. Todos os autores declaram para os devidos fins que são de suas responsabilidades o conteúdo relacionado a todos os aspectos do manuscrito submetido ao OBJN. Garantem que as questões relacionadas com a exatidão ou integridade de qualquer parte do artigo foram devidamente investigadas e resolvidas. Eximindo, portanto o OBJN de qualquer participação solidária em eventuais imbróglios sobre a matéria em apreço. Todos os autores declaram que não possuem conflito de interesses, seja de ordem financeira ou de relacionamento, que influencie a redação e/ou interpretação dos achados. Essa declaração foi assinada digitalmente por todos os autores conforme recomendação do ICMJE, cujo modelo está disponível em http://www. objnursing.uff.br/normas/DUDE_final_13-06-2013.pdf

Recebido: $27 / 01 / 2016$

Revisado: $31 / 01 / 2017$

Aprovado: 06/02/2017 